(C)2003 Marcel Dekker, Inc. All rights reserved. This material may not be used or reproduced in any form without the express written permission of Marcel Dekker, Inc.

ANALYTICAL LETTERS

Vol. 36, No. 9, pp. 1921-1938, 2003

\title{
Prussian Blue Modified Carbon Nanotube Paste Electrodes: A Comparative Study and a Biochemical Application
}

\author{
Francesco Ricci, ${ }^{1, *}$ Aziz Amine, ${ }^{2}$ Danila Moscone, ${ }^{1}$ \\ and Giuseppe Palleschi ${ }^{1}$ \\ ${ }^{1}$ Dipartimento Di Scienze e Tecnologie Chimiche, \\ Università di Roma Tor Vergata, Via della Ricerca \\ Scientifica, Rome, Italy \\ ${ }^{2}$ Faculté Des Sciences et Techniques de \\ Mohammedia, Morocco
}

\begin{abstract}
Prussian Blue modification of Single Walled Carbon Nanotubes and the successive assembling of paste electrodes is presented in this article for the first time. The electrochemical feature of such electrodes have been fully evaluated with $\mathrm{CV}$ and amperometric experiments. Prussian Blue Nanotube Paste electrodes showed a high sensitivity towards hydrogen peroxide with a LOD of $7.4 \times 10^{-6} \mathrm{M}$. They also proved to possess a strong stability even at
\end{abstract}

*Correspondence: Francesco Ricci, Dipartimento Di Scienze e Tecnologie Chimiche, Università di Roma Tor Vergata, Via della Ricerca Scientifica, 00133 Rome, Italy; E-mail: francesco.ricci@uniroma2.it.

1921

DOI: $10.1081 /$ AL-120023622

Copyright (c) 2003 by Marcel Dekker, Inc.
0003-2719 (Print); 1532-236X (Online) www.dekker.com 
basic pHs (i.e., pH 9 and 10) demonstrating no significant loss of signal after three days of continuous work. In addition, the loading in the paste mixture of glucose oxidase has brought to a sensitive tool for the detection of glucose in a range between 0.1 and $50 \mathrm{mM}$.

Key Words: Prussian blue; Nanotubes; Nanotube paste electrode; Hydrogen peroxide; Glucose oxidase; Glucose.

\section{INTRODUCTION}

Carbon nanotube is a novel carbon material discovered by Iijima in $1991^{[1]}$ and it has been found to have excellent electrode performances. ${ }^{[2]}$ Single walled carbon nanotubes constitute a new form of molecular diameter metallic semiconducting wire. Their high conductance, tensile strength, and chemical stability have attracted much attention ${ }^{[3]}$ and interest for many applications. ${ }^{[4-8]}$ Single wall carbon nanotubes, reported for the first time in 1993 were firstly studied and characterized as electrode material by two research groups. ${ }^{[9-11]}$ The electrodes were obtained casting a film of single wall carbon nanotubes on a glassy carbon electrode and were found to have an electrochemical activity towards some biomolecules such as dopamine, epinephrine, and ascorbic acid.

In a recent article by our research group an extended study of the electrochemical properties of carbon nanotubes paste electrodes has been presented. ${ }^{[12]}$ Paste electrodes were constructed mixing single walled carbon nanotubes with mineral oil. Performances of carbon nanotube paste were evaluated studying the parameters of cyclic voltammetry towards several electroactive molecules. Due to their high surface area ${ }^{[13,14]}$ single walled carbon nanotubes required a higher amount of mineral oil $(40 \%)$ in respect of what observed with graphite $(34 \%)^{[22]}$ and glassy carbon $(20 \%)^{[20]}$ in the assembling of paste electrodes. Moreover, electrodes showed an enhanced electroactivity towards hydrogen peroxide, dopamine, NADH oxidation in respect of classic graphite based paste electrodes. ${ }^{[12]}$ This behavior together with the compatibility with biological tissues makes the nanotubes suitable for the development of new chemical sensors and biosensors. Nowadays the largest number of biosensors are based on the use of oxidase enzymes that catalyze the oxidation of a substrate with the consequence reduction of $\mathrm{O}_{2}$ to hydrogen peroxide. A rapid, interference free, and precise detection of $\mathrm{H}_{2} \mathrm{O}_{2}$ (whose concentration is proportional to the substrate concentration) is then always required to give an accurate measure of the enzymatic substrate which represents in much cases the analyte. For this reason 
Prussian Blue, a selective catalyst of the $\mathrm{H}_{2} \mathrm{O}_{2}$ reduction, has been fully investigated during last decade. ${ }^{[15-18,27,28]}$ The modification of an electrode surface with a layer of $\mathrm{PB}$ makes in fact it possible to measure $\mathrm{H}_{2} \mathrm{O}_{2}$ at low applied potential (around $0.0 \mathrm{~V}$ ) and to greatly decrease any electrochemical interference, as demonstrated in a previous article. ${ }^{[19]}$

In this work, we report for the first time the modification of single walled carbon nanotube powder with Prussian Blue and the successive assembling of composite electrode for $\mathrm{H}_{2} \mathrm{O}_{2}$ detection. The electrochemical behavior of these probes has been fully characterized by cyclic voltammetry in terms of surface charge, peak currents, formal potential, and $\triangle \mathrm{Ep}$. Amperometric experiments have been carried out to evaluate the $\mathrm{H}_{2} \mathrm{O}_{2}$ response and analytical parameters such as detection limit, linear range, RSD, and sensitivity have been evaluated. A comparison with PB modified graphite electrodes is also presented. This is in our knowledge the first article reporting the direct modification of carbon nanotubes with an electrochemical mediator. An application obtained by simply loading aliquots of oxidase enzyme in the paste mixture is also presented.

\section{EXPERIMENTAL}

\section{Apparatus}

Amperometric measurements were carried out using a VA 641 amperometric detector (Metrohm, Herisau, Switzerland), connected to a $X$ - $t$ recorder (L250E, Linseis, Selb, Germany). The electrochemical cell was assembled with a conventional three-electrode system: Carbon Nanotube Paste working electrode (3-mm diameter), an $\mathrm{Ag} / \mathrm{AgCl} / \mathrm{KCl}$ (3 M) reference electrode and a Pt counter electrode. Cyclic voltammetry (CV) and chronoamperometry experiments were performed using an Autolab electrochemical system (Eco Chemie, Utrecht, The Netherlands) equipped with PGSTAT-12 and GPES software (Eco Chemie, Utrecht, The Netherlands).

\section{Reagents}

Single Wall Carbon Nanotubes (CNT) Carbolex (purity 50-70\%) and graphite particles (powder 1-2 $\mu \mathrm{m}$ ) were purchased from Aldrich (Steinheim, Germany). Mineral oil was obtained from Fluka (Buchs, Switzerland). All chemicals from commercial source were of analytical 
grade. All solutions were prepared with $0.05 \mathrm{M}$ phosphate buffer $+0.1 \mathrm{M}$ $\mathrm{KCl}, \mathrm{pH}$ 7.4. Standard solutions were daily prepared in same buffer. For $\mathrm{pH}$ effect studies borate buffer $(0.05 \mathrm{M}+\mathrm{KCl} 0.1 \mathrm{M}, \mathrm{pH} 9.0$ and $\mathrm{pH} 10)$ was also used.

Glucose Oxidase (GOx) (EC 1.1.3.4, type VII from Aspergillus Niger, 185 units/mg), was Purchased from Sigma (St. Luis, MO).

\section{Preparation of CNT Modified With PB}

The PB was chemically synthesized in the presence of nanotube powder starting from its precursors $\mathrm{K}_{3} \mathrm{Fe}(\mathrm{CN})_{6}$ and $\mathrm{FeCl}_{3}$ as follows: the nanotube powder $(1 \mathrm{~g})$ was suspended in $10 \mathrm{~mL}$ of a solution of $\mathrm{K}_{3} \mathrm{Fe}(\mathrm{CN})_{6} 0.10 \mathrm{M}$ in $10 \mathrm{mM} \mathrm{HCl}$. Next $10 \mathrm{~mL}$ of a $0.10 \mathrm{M}$ solution of $\mathrm{FeCl}_{3}$ in $10 \mathrm{mM} \mathrm{HCl}$ were added and the resulting mixture was stirred for $10 \mathrm{~min}$. The nanotube powder (with adsorbed PB) was then collected by filtration and washed with $10 \mathrm{mM} \mathrm{HCl}$ until the washing solution became colorless and then dried in oven at $100^{\circ} \mathrm{C}$ for $1.5 \mathrm{~h}$. The powder modified with Prussian Blue (referred as PBNT) was stored dark in a desiccator at room temperature. For graphite modification the same procedure was adopted.

\section{CNT Paste Electrodes Preparation}

The nanotube paste mixture was prepared mixing nanotube powder and mineral oil at a fixed ratio of $60 / 40 \mathrm{w} / \mathrm{w}$ respectively. The paste was carefully hand-mixed in a mortar and then packed into a cavity (3-mm diameter; 2-mm depth) at the end of a Teflon tube. Electrical contact was provided by a copper wire connected to the paste in the inner hole of the tube. The paste was kept at room temperature in a desiccator until used. Carbon Nanotube Paste electrodes modified with Prussian Blue (referred as PBNTPEs) were prepared by hand-mixing mineral oil (40\%) and a mixture of PBNT/NT $(60 \%)$. Prussian Blue graphite paste electrodes (referred as PBgraphitePEs) have been obtained by mixing PB modified graphite $(66 \%)$ and mineral oil $(34 \%)$.

\section{Preparation of PBNTP Glucose Biosensor}

Biosensors were prepared by hand mixing $60 \mathrm{mg}$ of $\mathrm{PBNT} / \mathrm{NT} /$ enzyme mixture with $40 \mathrm{mg}$ of mineral oil and then mixed continuously 
until a homogeneous paste was obtained. The PBNT/NT/enzyme mixture had the following weight composition: $22.5 \%$ PB-NT, $72.5 \%$ NT and 5\% glucose oxidase. An aliquot of the final paste filled the tip of the electrode; the remaining was kept in an aluminium foil at $4^{\circ} \mathrm{C}$ until reused.

\section{$\mathrm{H}_{2} \mathrm{O}_{2}$ and Enzymatic Substrate Measurements}

Measurements of $\mathrm{H}_{2} \mathrm{O}_{2}$ and enzymatic substrate were performed using amperometric batch analysis in a stirred phosphate buffer solution $(20 \mathrm{~mL})$ with an applied potential of $0.0 \mathrm{~V}$ vs. $\mathrm{Ag} / \mathrm{AgCl}$. When a stable baseline was reached, the analyte was added and the response recorded.

\section{RESULTS AND DISCUSSION}

\section{Characterization of PB Modified Carbon Nanotubes Paste Electrodes}

In a previous article ${ }^{[12]}$ that deals with the use of Single Walled Carbon Nanotubes for the assembling of Carbon Nanotube Paste electrodes, it was already demonstrated that the best paste composition was $60 / 40$ Nanotubes/mineral oil w/w. The physical properties ${ }^{[23]}$ of Carbon nanotubes (CNTs) and their unique morphology are much different in respect of graphite powder and a complete study of their electrochemical behavior upon PB modification is not yet present in literature.

The CNTs here used are reported to have cylindrical geometry with a pore diameter of $1-2 \mathrm{~nm}$ and a length of microns. The surface area of CNTs calculated experimentally using BET method is $300 \mathrm{~m}^{2} / \mathrm{g},{ }^{[13,14]}$ while for graphite powder was ca. $10 \mathrm{~m}^{2} / \mathrm{g} \cdot{ }^{[25]} \mathrm{CNTs}$ were modified with Prussian Blue using the same procedure already optimized in previous articles ${ }^{[20-22]}$ dealing with graphite and glassy carbon, which has brought to high electrochemical activity and good stability of the Prussian Blue layer. In Fig. 1 is shown the cyclic voltammetry obtained with the PBNTPE prepared with $60 \%$ of PB modified carbon nanotube and $40 \%$ of mineral oil, which clearly shows the cathodic and anodic current peak due to the reduction and oxidation of Prussian Blue at the electrode surface.

Table 1a summarizes some of the electrochemical parameters obtained from cyclic voltammetry with PBNTPEs and with PBgraphite 
(C)2003 Marcel Dekker, Inc. All rights reserved. This material may not be used or reproduced in any form without the express written permission of Marcel Dekker, Inc.

1926

Ricci et al.

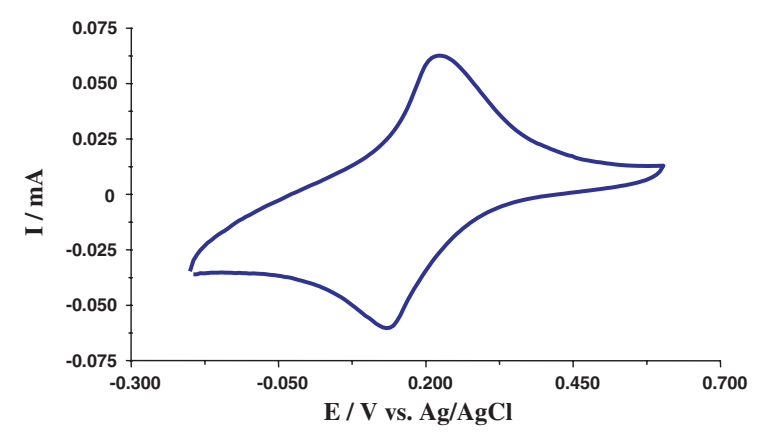

Figure 1. Cyclic voltammetry of PBNTPE. Paste composition: $40 \%$ mineral oil, $60 \%$ PBNT. Phosphate buffer $0.05 \mathrm{M}+\mathrm{KCl} 0.1 \mathrm{M}, \mathrm{pH} 7.4$. Scan rate $5 \mathrm{mV} / \mathrm{s}$. Potential range $-0.2 ;+0.5 \mathrm{~V}$ vs. $\mathrm{Ag} / \mathrm{AgCl}$.

Table 1a. Comparison between PBNTPEs and PBgraphitePEs. Cyclic voltammetry parametrs, phosphate buffer $0.05 \mathrm{M}+\mathrm{KCl} 0.1 \mathrm{M}, \mathrm{pH}$ 7.4. Scan rate (i.e., $\nu=50 \mathrm{mV} / \mathrm{s}$, potential range $-0.2 ;+0.5 \mathrm{~V}$ vs. $\mathrm{Ag} / \mathrm{AgCl}$. See text for details on paste composition. Underscript: $\mathrm{a}=$ anodic, $\mathrm{c}=$ cathodic.

\begin{tabular}{lcc}
\hline Parameters & PBNTPEs & PBgraphitePEs \\
\hline $\mathrm{I}_{\mathrm{a}}(\mathrm{nA})$ & 272 & 61 \\
$\mathrm{I}_{\mathrm{c}}(\mathrm{nA})$ & 265 & 58 \\
$\Delta \mathrm{E}_{\mathrm{p}}(\mathrm{mV})$ & 228 & 124 \\
$\mathrm{Q}_{\mathrm{a}} / \mathrm{A}\left(\mathrm{mC} / \mathrm{cm}^{2}\right)$ & 21.7 & 1.3 \\
$\mathrm{Q}_{\mathrm{c}} / \mathrm{A}\left(\mathrm{mC} / \mathrm{cm}^{2}\right)$ & 20.8 & 1.4 \\
$\mathrm{E}_{\mathrm{f}}(\mathrm{mV})$ & 170 & 185 \\
$\mathrm{Ip}_{\mathrm{c}} / \mathrm{Ip}$ & 0.97 & 0.95 \\
$\partial(\log \mathrm{Ip}) / \partial(\log v)_{\mathrm{a}}$ & 0.65 & 0.56 \\
$\partial(\log \mathrm{Ip}) / \partial(\log v)_{\mathrm{c}}$ & 0.47 & 0.49 \\
\hline
\end{tabular}

PEs. Relative amount of mineral oil and graphite is as previously reported. ${ }^{[22]}$

According to the equation: $\mathrm{Q}=\mathrm{nFA} \Gamma$ where $\mathrm{Q}$ is the anodic or cathodic charge, $n=4, \mathrm{~F}$ is Faraday's constant and $\mathrm{A}$ is the effective area of the electrode, which is assumed to be equivalent to its geometric area $\left(0.07 \mathrm{~cm}^{2}\right)$, the charge density of the electrode $(\mathrm{Q} / \mathrm{A})$ is directly proportional to the total amount of $\mathrm{PB}$ on the electrode surface $(\Gamma)$. Values of charge density $(\mathrm{Q} / \mathrm{A})$ for PBNTPE are about $22 \mathrm{mC} / \mathrm{cm}^{2}$ while for PBgraphite paste the value found was ca. $1.3 \mathrm{mC} / \mathrm{cm}^{2}$. This is 
probably due to the fact that CNT possess a very high surface area and a large amount of PB can be easily adsorbed. This seems also to be confirmed by the values of peak currents of PBNTPE which are ca. 4-5 times higher than those of PBgraphite PE.

The dependence of the potential scan rate on the peak reduction current has been then evaluated. The $\log (\mathrm{Ip})$ vs. $\log (v)$ plot, in a range between 2 and $200 \mathrm{mV} / \mathrm{s}$, gives slopes of 0.65 and 0.47 for the anodic and cathodic peak respectively demonstrating a diffusion controlled process as in the case of an adsorbed mediator. The $\triangle E p$ on the PBNTPEs is $228 \mathrm{mV}$, ca. $100 \mathrm{mV}$ higher than that obtained with PBgraphitePE, demonstrating a slower electrode transfer kinetic in part due to the much higher amount of PB.

The formal potential of PBNTPEs is almost the same of that obtained with PB graphitePEs. For this reason the same applied potential $(0.0 \mathrm{~V})$ already chosen ${ }^{[22]}$ for PBgraphitePEs has been selected for further amperometric experiments.

In Table $1 \mathrm{~b}$ are summarized the analytical parameters obtained for amperometric measurements of hydrogen peroxide using PBNTPEs and PBgraphitePEs. For PB graphite paste electrodes sensitivity towards hydrogen peroxide was found to be $428 \mathrm{~mA} / \mathrm{M} \mathrm{cm}^{2}$ while for PBNTPEs is about $218 \mathrm{~mA} / \mathrm{M} \mathrm{cm}^{2}$. This seems to be in contrast with what observed in $\mathrm{CV}$ experiments where $\mathrm{PB}$ amount was ca. 4-5 times higher for PBNTPEs.

This difference could be in part due to the larger presence of non conductive material (i.e., mineral oil and the PB itself) at the PBNTPEs but also to a slow electrode kinetics of nanotube particles. This is also confirmed by the high current noise observed (i.e., $50 \mathrm{nA}$ ) that makes the

Table 1b. Comparison between PBNTPEs and PBgraphitePEs. Amperometric parameters, batch measurements in $20 \mathrm{~mL}$ phosphate buffer $0.05 \mathrm{M}+\mathrm{KCl} 0.1 \mathrm{M}, \mathrm{pH}$ 7.4. Applied potential $0.0 \mathrm{~V}$ vs. $\mathrm{Ag} / \mathrm{AgCl}$.

\begin{tabular}{|c|c|c|}
\hline Parameters & PBNTPEs & PBgraphitePEs \\
\hline Linear range $(\mathrm{M})$ & $10^{-5}-5 \times 10^{-3}$ & $5 \times 10^{-7}-5 \times 10^{-3}$ \\
\hline $\mathrm{LOD}(\mathrm{M})$ & $1.0 \times 10^{-5}$ & $5 \times 10^{-7}$ \\
\hline Noise (nA) & 50 & 5 \\
\hline Sensitivity $\left(\mathrm{mA} / \mathrm{M} \mathrm{cm}{ }^{2}\right)$ & 218 & 428 \\
\hline Response time (s) & 5 & 15 \\
\hline $\begin{array}{l}\text { Time to stabilize the } \\
\text { baseline current (min) }\end{array}$ & 80 & 150 \\
\hline
\end{tabular}


detection limit of PBNTPEs towards hydrogen peroxide much higher than that obtained with PB graphite paste electrode.

Taking into account the results obtained in a previous article with the PB modified glassy carbon paste electrodes, ${ }^{[20]}$ we decreased the total amount of PB in the paste by mixing PBNT with unmodified NT before adding mineral oil. In fact, in the case of glassy carbon paste electrodes, by doing this, a better electrochemical behavior both in voltammetric and amperometric experiments has been observed due to the improved electrode kinetic.

The effect of the paste composition on the electrochemical behavior of PBNTPEs was then evaluated studying the cyclic voltammetric parameters and the amperometric responses to $\mathrm{H}_{2} \mathrm{O}_{2}$. Considering these results, the best paste composition has been selected and used for further experiments. Paste was always made keeping the mineral oil percentage at $40 \%$ and $60 \%$ for the PBNT/NT mixture. The compositions of the PBNT/NT mixture tested were as follows: 75/25, 50/50, 25/75, 10/90, $2 / 98, w / w$. In Table 2 are reported the cyclic voltammetric parameters obtained in phosphate buffer solution with all the mixtures prepared. Anodic and cathodic peak currents are, as it was expected, proportional to PB loading and increase with the increasing of the relative amount of PBNT. Same behavior is observed for the charge density of the electrode (Q). Amperometric parameters evaluated using Carbon Nanotube paste electrodes obtained with a mixture of PBNT/NT are summarized in Table 3. No improvement in sensitivity has been achieved in respect of that obtained using only PBNT, but the presence of non modified nanotube powder brings a faster electrode kinetics with a decrease of the noise

Table 2. Cyclic voltammetry parameters upon paste composition. Paste was obtained mixing $40 \%$ of mineral oil and $60 \%$ of a mixture of PBNT/NT. Phosphate buffer $0.05 \mathrm{M}+\mathrm{KCl} 0.1 \mathrm{M}, \mathrm{pH}$ 7.4. Scan rate $50 \mathrm{mV} / \mathrm{s}$, range $-0.2 ;+0.5 \mathrm{~V}$ vs. $\mathrm{Ag} / \mathrm{AgCl}$.

\begin{tabular}{lccccc}
\hline $\begin{array}{l}\% \\
\text { PBNT/NT }\end{array}$ & $\begin{array}{c}\mathrm{I}_{\mathrm{a}} \\
(\mathrm{nA})\end{array}$ & $\begin{array}{c}\mathrm{I}_{\mathrm{c}} \\
(\mathrm{nA})\end{array}$ & $\begin{array}{c}\Delta \mathrm{Ep} \\
(\mathrm{mV})\end{array}$ & $\begin{array}{c}\mathrm{Q}_{\mathrm{a}} / \mathrm{A} \\
\left(\mathrm{mC} / \mathrm{cm}^{2}\right)\end{array}$ & $\mathrm{E}_{1 / 2}$ \\
\hline 100 & 272 & 265 & 228 & 21.7 & 170 \\
75 & 230 & 199 & 203 & 17.5 & 168 \\
50 & 135 & 122 & 179 & 10.8 & 167 \\
25 & 73 & 68 & 119 & 5.4 & 170 \\
10 & 18 & 18 & 102 & 1.4 & 172 \\
2 & 10 & 10 & 125 & 0.8 & 177 \\
\hline
\end{tabular}


C일 2003 Marcel Dekker, Inc. All rights reserved. This material may not be used or reproduced in any form without the express written permission of Marcel Dekker, Inc.

Modified Nanotube Paste Electrodes

1929

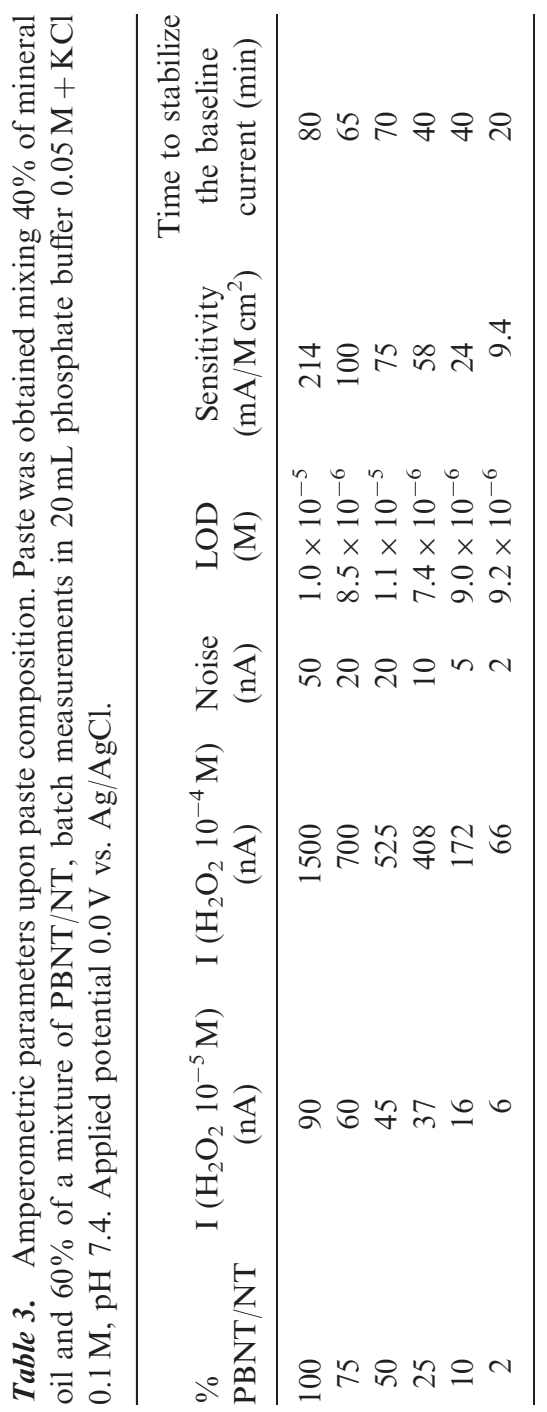


current and of the detection limit. For this reason a paste obtained with a mixture of PBNT/NT 25/75 w/w was selected and used for further experiments. Table 4 summarizes the analytical characteristics of this PBNTPE towards $\mathrm{H}_{2} \mathrm{O}_{2}$ reduction: i.e., detection limit (reported as two times the background noise), linearity range, sensitivity variations (related to the slope variation of calibration curves continuously carried out for $8 \mathrm{~h}$ ), and reproducibility (reported as the RSD of the current values due to the $\mathrm{H}_{2} \mathrm{O}_{2}$ reduction by 4 different sensors obtained from the same paste matrix). Response time, expressed as the time needed to reach $90 \%$ of the steady state current, and the time necessary to obtain a stable baseline current, are also reported, while in Fig. 2 are shown some original amperometric recordings.

Comparison with the amperometric parameters of $\mathrm{PB}$ modified graphite paste electrodes shows how the use of PB modified carbon nanotubes does not bring any important improvement on the sensitivity towards hydrogen peroxide. Moreover a higher detection limit was observed using PB modified nanotube. This is greatly due to the much higher noise current obtained in the case of PBNTPEs, probably caused by a slow electrode kinetic of Nanotube particles. This property of Single Walled CNTs (SWCNT) has been already observed by some research groups and an article by Avouris ${ }^{[26]}$ clarified the reason for such behavior. In this article, the strong background impedance of the SWNTs is attributed to the fact that the current synthetic schemes for SWNTs generate mixtures of metallic $(\mathrm{m})$ and semiconducting (s) nanotubes, where the latter is responsible for a leakage in conductance that negatively affects the electrode kinetic. The slow electrode kinetics of the PBNTPEs due to the large amount of mineral oil and to the presence of semiconductor SWNT seems to represent the major drawback of this material to assemble PB based amperometric sensors.

\section{Stability of PBNTPEs}

Stability of the PB deposited is one of the most important parameters needed to evaluate the possible use of these sensors in biosensors assembling. We have already demonstrated with other materials (i.e., glassy carbon ${ }^{[20]}$ and graphite ${ }^{[22]}$ that the PB modification procedure here adopted has brought a good stability of $\mathrm{PB}$ in a broad $\mathrm{pH}$ range.

PBNTPEs were then studied at basic $\mathrm{pHs}$ in order to evaluate any possible improvement of the $\mathrm{pH}$ stability. Sensors were left in a batch system with the applied potential $(0.0 \mathrm{~V})$, and amperometric 
C일 2003 Marcel Dekker, Inc. All rights reserved. This material may not be used or reproduced in any form without the express written permission of Marcel Dekker, Inc.

Modified Nanotube Paste Electrodes

1931

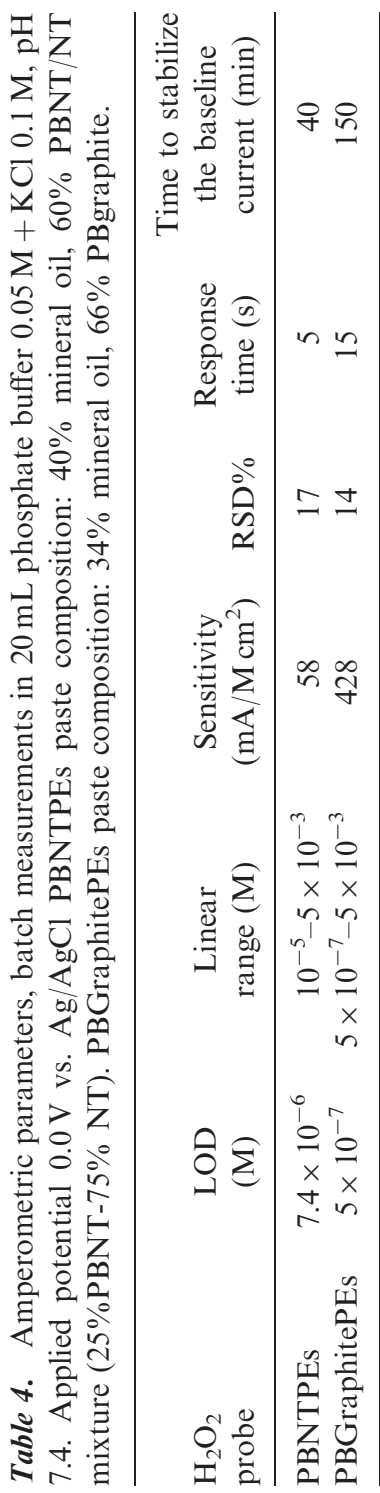


(C)2003 Marcel Dekker, Inc. All rights reserved. This material may not be used or reproduced in any form without the express written permission of Marcel Dekker, Inc.

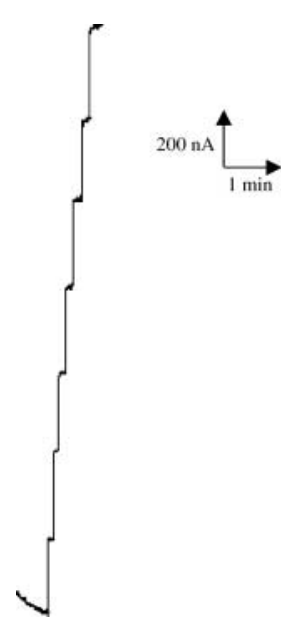

Figure 2. Amperometric responses towards hydrogen peroxide. Loadings of $10^{-4} \mathrm{M}$ of hydrogen peroxide. Batch measurements in $20 \mathrm{~mL}$ phosphate buffer $0.05 \mathrm{M}+\mathrm{KCl} 0.1 \mathrm{M}, \mathrm{pH}$ 7.4. Applied potential $0.0 \mathrm{~V}$ vs. $\mathrm{Ag} / \mathrm{AgCl}$. PBNTPEs paste composition: 40\% mineral oil, $60 \%$ PBNT/NT mixture $(25 \%$ PBNT-75\% NT).

measurements of fixed concentration of hydrogen peroxide $\left(10^{-4} \mathrm{M}\right)$ were performed every two hours. During the night sensors were kept under stirring, with the applied potential, in a $5 \times 10^{-4} \mathrm{M}$ hydrogen peroxide solution and every morning the solution was renewed. pH's values tested were 8,9 , and 10 . At $\mathrm{pH} 8$ (not shown) after 3 days of continuous work no decrease of the initial signal was observed. At pH 9 the same behavior was observed and no inactivation was detected after a total of $52 \mathrm{~h}$ (Fig. 3a). Same strong stability of the PB deposited was found by using cyclic voltammetry. 250 continuous cycles were performed at the same $\mathrm{pH}$ values (i.e., 8 and 9 ) and a very little decrease on the peak currents of the last scan was observed in both cases. At $\mathrm{pH} 10$ a decrease of the initial signal for $\mathrm{H}_{2} \mathrm{O}_{2}$ of $25 \%$ was detected after three days of continuous work. This is in our knowledge the best operative stability of any $\mathrm{PB}$ modified material at basic $\mathrm{pH}$. In Fig. $3 \mathrm{a}$ and $3 \mathrm{~b}$ a direct comparison with PBgraphitePEs is presented which clearly shows the better operative stability of nanotubes based PB paste electrodes.

One of the most attractive properties of carbon nanotubes is their robustness that makes them similar to a diamond material. Single walled nanotubes are constituted of hollow cylindrically wound graphene sheets 
C2003 Marcel Dekker, Inc. All rights reserved. This material may not be used or reproduced in any form without the express written permission of Marcel Dekker, Inc.

Modified Nanotube Paste Electrodes

1933
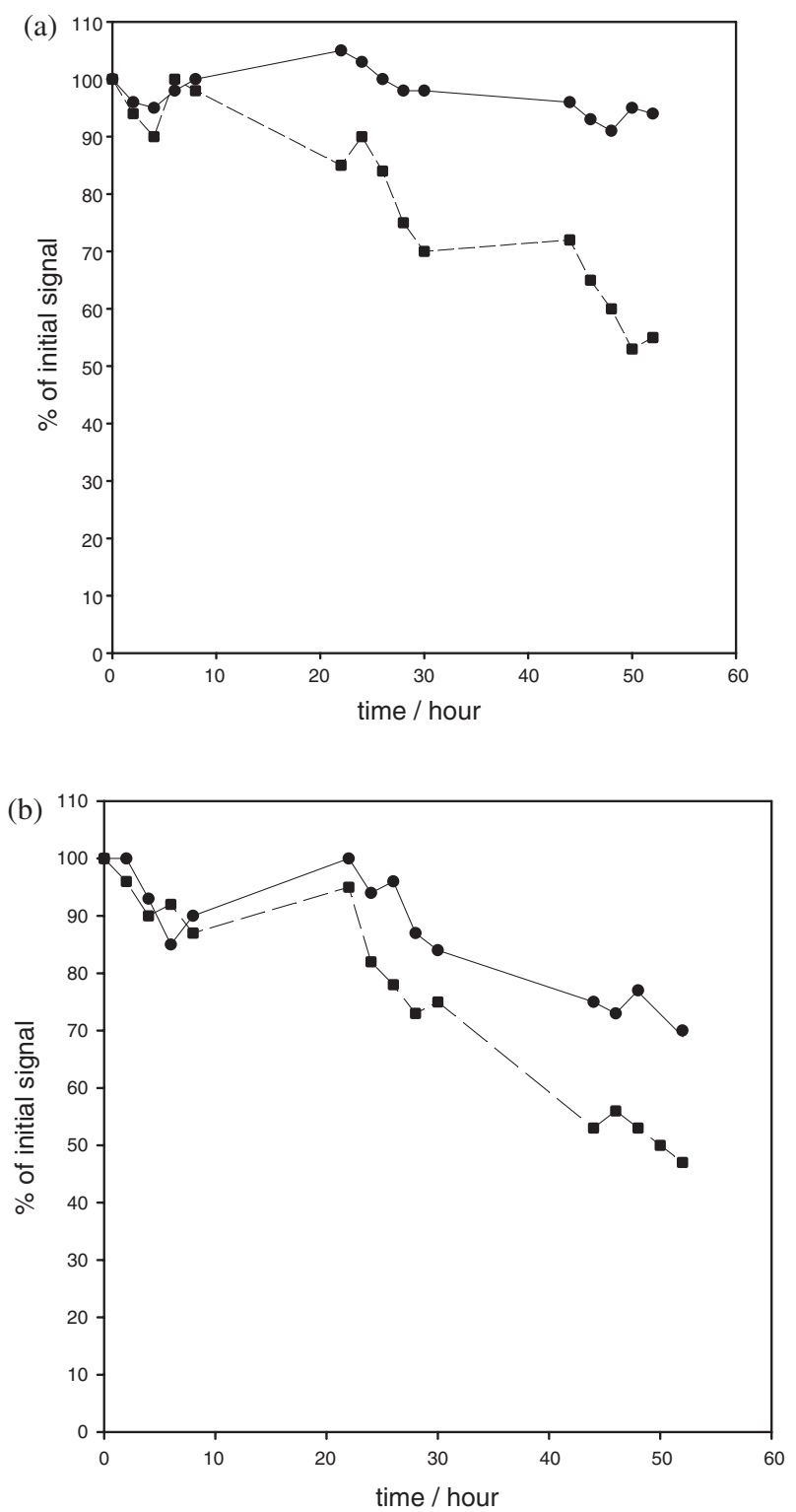

Figure 3. Stability studies of PBNTPEs. Continuous amperometric measurements of hydrogen peroxide. (a) Borate buffer $0.05 \mathrm{M}+\mathrm{KCl} 0.1 \mathrm{M}, \mathrm{pH} \mathrm{9.} \mathrm{(b)}$ Borate buffer $0.05 \mathrm{M}+\mathrm{KCL} 0.1 \mathrm{M}, \mathrm{pH} 10$. PBNTPEs: paste composition: $40 \%$ mineral oil, $60 \% \quad \mathrm{PBNT} / \mathrm{NT}$ mixture $(25 \% \mathrm{PBNT}-75 \% \quad \mathrm{NT})$. PBGraphitePEs: paste composition: 66\% mineral oil, 34\% PBgraphite. 
Table 5. Amperometric parameters towards glucose. Amperometric parameters, batch measurements in $20 \mathrm{~mL}$ phosphate buffer $0.05 \mathrm{M}+\mathrm{KCl} 0.1 \mathrm{M}$, pH 6.0. Applied potential $0.0 \mathrm{~V}$ vs. $\mathrm{Ag} / \mathrm{AgCl}$, PBNTPEs $+5 \%$ glucose oxidase, PBgraphitePEs $+5 \%$ glucose oxidase (see text for details).

\begin{tabular}{lcc}
\hline & $\begin{array}{c}\text { PB-NT glucose } \\
\text { biosensor }\end{array}$ & $\begin{array}{c}\text { PB-graphite } \\
\text { glucose biosensor }\end{array}$ \\
\hline Linear range (M) & $10^{-4}-5 \times 10^{-2}$ & $10^{-4}-2 \times 10^{-2}$ \\
LOD (M) & $7 \times 10^{-5}$ & $10^{-4}$ \\
Sensitivity (mA/M cm ${ }^{2}$ ) & 3.3 & 2.3 \\
Response time (s) & 5 & 15 \\
RSD\% & 18 & 14 \\
Time to stabilize the & & 150 \\
$\quad$ baseline current (min) & 45 & \\
\hline
\end{tabular}

that tend to assemble in ropes of nanotubes. ${ }^{[30]}$ Probably, during PB modification, intercalation of PB crystals, that according to Keggin and Miles ${ }^{[29]}$ has a basic cubic structure of the dimension equal to 10.2 $\AA$, occurs in the inner space of the cylinders or in the space between nanotubes bundles. Carbon nanotubes are reported to be well resistant towards oxidant compounds and so no fragmentation of the structure should occur during stability studies at high $\mathrm{H}_{2} \mathrm{O}_{2}$ concentration. This means that the PB intercalated in the pores between CNT remains protected during the whole experiment. In the case of graphite instead, during $\mathrm{PB}$ modification the PB crystals intercalate the graphite sheets, but a desegregation of the original structure could generate after prolonged exposure to high concentration of hydrogen peroxide, reducing the protective action to $\mathrm{PB}$ crystals and decreasing the stability of the PB modified sensor at basic pHs values.

\section{Oxidase Application}

Glucose Oxidase enzyme was loaded in the PBNTPE mixture by a mean of $5 \%$, to assemble a glucose biosensor. Analytical performances of this probe are summarized in Table $5, \mathrm{LOD}(\mathrm{S} / \mathrm{N}=2)$ was estimated to be $7 \times 10^{-5} \mathrm{M}$, the linear range was up to $10^{-2} \mathrm{M}$ and the sensitivity was $3.3 \mathrm{~mA} / \mathrm{M} \mathrm{cm}^{2}$. A comparison with what as obtained using graphite as electrodic material shows the better behavior of the PB nanotube 
glucose biosensors. This is probably due to the high biocompability of carbon nanotubes, already observed in other articles, ${ }^{[24,31]}$ which causes a retention of the enzyme activity overcoming the effect of the high noise current.

\section{CONCLUSIONS}

The present investigation describes for the first time the modification with $\mathrm{PB}$ of single walled carbon nanotubes and the assembling of paste electrodes. Voltammetric and amperometric parameters have been fully characterized and compared with those obtained with PB graphite. The PBNTPEs resulted in low electrode kinetics that did not improve the analytical performance of the sensors towards hydrogen peroxide detection. At $0.0 \mathrm{~V}$ they exhibited in fact detection limits higher than that observed with graphite as electrode materials. Sensitivity was found to be in the same range of PBgraphite paste electrodes.

PB nanotube electrodes showed a poorer electrochemical behavior and a lower sensitivity even in respect of what obtained with paste electrodes studied in a previous work using PB modified Glassy Carbon particles as electrode material. ${ }^{[20]}$ By now, in our opinion, glassy carbon particles have resulted to be, if compared with graphite and carbon nanotube, the best electrode material for assembling of PB based paste sensors.

Despite this, PBNTPEs proved to possess a better stability at basic pH's. We have proposed a physical explanation for this behavior based on the peculiar structure of SWNT and on their unique resistance. This characteristic makes this electrodic material an attractive tool for the assembling of stable and robust sensors.

By loading on the paste mixture $5 \%$ of glucose oxidase, a glucose biosensor was also assembled and its analytical parameters evaluated. The possible use of different enzymes is at present in progress in our laboratory to verify the biocompability of carbon nanotubes for the assembling of enzyme based biosensors.

\section{ACKNOWLEDGMENT}

Aziz Amine is grateful to the University of Rome Tor Vergata for financial support. 


\section{REFERENCES}

1. Iijima, S. Helical microtubules of graphitic carbon. Nature 1991, 354, 56-58.

2. Britto, P.J.; Santhanam, K.S.V.; Rubio, A.; Alonso, J.A.; Ajayan, P.M. Improved charge transfer at carbon nanotube electrodes. Adv. Mater. 1999, 11, 154-157.

3. Chen, J.H.; Li, W.Z.; Wang, D.Z.; Yang, S.X.; Wen, J.G.; Ren, Z.F. Electrochemical characterization of carbon nanotubes as electrode in electrochemical double-layer capacitors. Carbon 2002, 40, 1193-1197.

4. Che, G.; Lakshmi, B.B.; Martin, C.R.; Fisher, E.R. Metal nanocluster-filled carbon nanotubes: catalytic properties and possible applications in electrochemical energy storage and production. Langmuir 1999, 15, 750-758.

5. Dillon, A.C.; Jones, K.M.; Bekkedahl, T.A.; Kiang, C.H.; Bethune, D.S.; Heben, M.J. Storage of hydrogen in single-wall carbon nanotubes. Nature 1997, 386, 377-379.

6. Wildoer, J.; Venema, L.; Rinzler, A.; Smalley, R.; Dekker, C. Electronic structure of atomically resolved carbon nanotubes. Nature 1998, 391, 59-62.

7. Ren, Z.F.; Huang, Z.P.; Xu, J.W.; Wang, J.H.; Bush, P.; Siegal, M.P. Synthesis of large arrays of well-aligned carbon nanotubes. Science 1998, 282, 1105-1107.

8. Kong, J.; Franklin, N.R.; Zhou, C.; Chapline, M.G.; Peng, S.; Cho, K. Nanotube molecular wires as chemical sensors. Science 2000, 287, 622-625.

9. Liu, C.Y.; Bard, A.J.; Wudl, F. Electrochemical characterization of films of single-walled carbon nanotubes and their possible application in supercapacitors. Electrochem. Solid State Lett. 1999, 2, 577-582.

10. Luo, G.; Li, Z.; Wei, F.; Xiang, L.; Jin, Y. Catalysts effect on morphology of carbon nanotubes prepared by catalytic chemical vapor deposition in a nano-agglomerate bed. Physica B 2002, 323, 314-317.

11. Luo, G.; Shi, Z.; Li, N.; Gu, Z.; Zhuang, Q. Investigation of the electrochemical and electrocatalytic behavior of single-wall carbon nanotube film on a glassy carbon electrode. Anal. Chem. 2001, 73, 915-920.

12. Valentini, F.; Amine, A.; Orlanducci, S.; Terranova, M.L.; Palleschi, G. Anal. Chem. 2003, in press.

13. Wong, S.S.; Joselevich, E.; Woolley, A.T.; Cheung, C.; Li, C.; Lieber, C.M. Covalently functionalized nanotubes as 
nanometer-sized probes in chemistry and biology. Nature 1998, $34,52-55$.

14. Peigney, C.H.; Laurent, E.; Bacsa Flahaut, R.R.; Rousset, A. Specific surface area of carbon nanotubes and bundles of carbon nanotubes. Carbon 2001, 39, 507-514.

15. Itaya, K.; Akahoshi, H.; Toshima, S. Electrochemistry of prussian blue modified electrodes: an electrochemical preparation method. J. Electrochem. Soc. 1982, 129, 1498-1501.

16. Itaya, K.; Shoji, N.; Uchida, I. Catalysis of the reduction of molecular oxygen to water at prussian blue modified electrodes. J. Am. Chem. Soc. 1984, 106, 3423-3429.

17. Karyakin, A.A.; Karyakina, E.E.; Gorton, L. The electrocatalytic activity of prussian blue in hydrogen peroxide reduction studied using wall-jet cell with continuous flow. J. Electroanal. Chem. 1998, 456, 97-104.

18. Karyakin, A.A.; Karyakina, E.E. Prussian blue based "artificial peroxidase" as a transducer for hydrogen peroxide detection. Application of biosensors sens. Actuators B 1999, 57, 268-273.

19. Ricci, F.; Amine, A.; Palleschi, G.; Moscone, D. Prussian blue based screen printed biosensors with improved characteristics of long-term lifetime and $\mathrm{pH}$ stability. Biosens. Bioelectron. 2003, 18, 165-174.

20. Ricci, F.; Goncalves, C.; Amine, A.; Gorton, L.; Palleschi, G.; Moscone, D. Electroanalytical study of prussian blue modified glassy carbon paste electrodes. Electroanalysis 2002, accepted.

21. Ricci, F.; Amine, A.; Moscone, D.; Tuta, C.; Ciucu, A.; Palleschi, G. Anal. Chim. Acta 2003, 485, 111-120.

22. Moscone, D.; D’Ottavi, D.; Compagnone, D.; Palleschi, G.; Amine, A. Construction and analytical characterization of prussian bluebased carbon paste electrodes and their assembly as oxidase enzyme sensors. Anal. Chem. 2001, 73, 2529-2535.

23. Saito, R.; Dresselhaus, G.; Dresselhaus, M.S. Physical Properties of Carbon Nanotubes; Imperial College Press: London, 1998.

24. Davis, J.J.; Coles, R.J.; Hill, H.A.O. Protein electrochemistry at carbon nanotube electrodes. J. Electroanal. Chem. 1997, 440, 279-282.

25. Firm documentation. Aldrich (USA).

26. Avouris, P. Carbon nanotube electronics. Chemical Physics 2002, 281, 429-445.

27. Garjonyte, R.; Malinauskas, A. Electrocatalytic reactions of hydrogen peroxide at carbon paste electrodes modified by 
C2003 Marcel Dekker, Inc. All rights reserved. This material may not be used or reproduced in any form without the express written permission of Marcel Dekker, Inc.

1938

Ricci et al.

some metal hexacyanoferrates. Sensors Actuators B 1998, 46, 236-241.

28. Zhang, X.; Wang, J.; Ogorevc, B.; Spichiger, U.S. Glucose nanosensor based on prussian-blue modified carbon-fiber cone nanoelectrode and an integrated reference electrode. Electroanalysis 1999, 11, 945-949.

29. Keggin, J.F.; Miles, F.D. Nature 1936, 137, 577.

30. Thostenson, E.T.; Ren, Z.; Chou, T.-W. Advances in the science and technology of carbon nanotubes and their composites: a review. Composites Science and Technology 2001, 61, 1899-1912.

31. Davis, J.J.; Green, M.L.H.; Hill, H.A.O.; Leung, Y.C.; Sadler, P.J.; Sloan, J.; Tsang, S.C. The immobilization of proteins in carbon nanotubes. Inorg. Chim. Acta 1998, 272, 261-266.

Received January 10, 2003

Accepted February 12, 2003 